\title{
Long-term study of gamete release in a broadcast-spawning holothurian: predictable lunar and diel periodicities
}

\author{
Annie Mercier ${ }^{1, *}$, Roberto H. Ycaza ${ }^{2}$, Jean-François Hamel ${ }^{1,3}$ \\ ${ }^{1}$ Ocean Sciences Centre (OSC), Memorial University of Newfoundland, St. John's, Newfoundland A1C 5S7, Canada \\ ${ }^{2}$ Investigaciones Especies Acuaticas (IEA), Klm 10 $\frac{1}{2}$ Via San Pablo, Santa Elena, Ecuador \\ ${ }^{3}$ Society for the Exploration and Valuing of the Environment (SEVE), 21 Phils Hill Road, Portugal Cove-St. Philips, \\ Newfoundland A1M 2B7, Canada
}

\begin{abstract}
Annual and monthly patterns of gamete release by the sea cucumber Isostichopus fuscus on the coast of Ecuador were studied to determine the proximal spawning cue and variations in reproductive output throughout the year. Several hundred newly collected individuals were monitored nearly every month for $4 \mathrm{yr}$. I. fuscus displayed a lunar spawning periodicity: 0.7 to $34.9 \%$ of individuals consistently spawned 1 to $4 \mathrm{~d}$ after the new moon. Spawning mostly occurred within one evening; however, some gamete release was often recorded over 2 to 4 consecutive evenings. Individuals maintained in captivity for several months retained their spawning periodicity and timing with the lunar cycle. Conversely, newly caught individuals that were shaded from the moonlight did not spawn, thus demonstrating the apparent lack of endogenous rhythms and prevalence of lunar luminance over other cues (i.e. tidal cycle, fluctuations in barometric pressure). On a spawning night, males typically initiated gamete release around sunset; females spawned just after the peak male broadcast. The percentage of spawning individuals was higher and a greater overlap between male and female peak spawning activity was observed during clear conditions compared with overcast conditions. The gonads of individuals that did not spawn in a given month showed a variety of maturity levels, including post-spawning, growth and mature gametogenic stages. Hence, the individual reproductive cycle is apparently longer than the monthly spawning periodicity observed at the population level, enabling I. fuscus populations to be reproductive year round.
\end{abstract}

KEY WORDS: Spawning · Periodicity - Lunar cycle · Reproductive synchrony · Holothurian · Echinoderm · Isostichopus fuscus

\section{INTRODUCTION}

Synchronous gamete release is prevalent as a means of maximizing reproductive success in broadcastspawning marine invertebrates (Babcock et al. 1992, Levitan 1995). The mechanisms through which this synchrony is achieved have been the subject of numerous studies, yielding a rich array of timing patterns. To date and for most species, spawning periodicities have typically been assessed by repeatedly sampling populations to measure gonado-somatic indices (GSI), gametogenic state and/or larval abundance in correlation with environmental factors (e.g. abundance of phytoplankton, temperature, photoperiod). Such studies have been conducted in holothurians (see review by Smiley et al. 1991) and other echinoderms (see review by Giese et al. 1991).

Many marine organisms display a lunar or semilunar component in some phase of their reproductive behaviour (Giese \& Kanatani 1987, Morgan 1995). Such rhythmic cycles have been shown to favour population persistence under conditions of high female: 
male ratios and/or low population size (Omori 1995). Some of the most famous examples are found in the swarming of grunions and palolo worms, which occurs predictably during specific months and lunar phases every year. For example, in Samoa, the Pacific palolo worm Palola (=Eunice) viridis consistently reproduces $7 \mathrm{~d}$ after the full moon in October or November (Caspers 1984). A number of other correlations between breeding activity and lunar rhythms are reported, with tidal oscillations and moonlight intensity being proposed as the major controlling influences. However, most studies have been too short in duration to identify the proximate factors responsible for the periodicity of gamete release.

In marine invertebrates, some of the most consistent evidence for lunar rhythms has been gathered from polychaete worms (Watson et al. 2000, Andries 2001, Bentley et al. 2001) and scleractinian corals (Jokiel et al. 1985, Babcock et al. 1986, Harrison \& Wallace 1990, Szmant 1991, Tanner 1996, McGuire 1998). In echinoderms, spawning has mainly been correlated with phytoplankton blooms and temperature (Giese et al. 1991); however, the influence of lunar phases has been demonstrated in echinoids (Pearse 1975, Coppard \& Campbell 2005), crinoids (Kubota 1981) and holothuroids (Babcock et al. 1992, Kubota 2000, Mercier et al. 2000). Within the examples cited above, data that positively correlate actual gamete release with the lunar cycle have only been obtained for some marine worms, the crinoid Oxycomanthus (= Comanthus) japonicus and for corals and associated invertebrates of the Great Barrier Reef, Australia. The present study investigated the monthly spawning pattern of the Galapagos sea cucumber Isostichopus fuscus over a period of $4 \mathrm{yr}$, by monitoring gamete release and correlating the results with lunar phases and other environmental factors.

Isostichopus fuscus is a deposit-feeding sea cucumber that is mainly found on reefs and sandy bottoms along the western coast of the Americas, from northern Peru to Baja California, Mexico (Sonnenholzner 1997, Gutierrez-Garcia 1999, Herrero-Pérezrul et al. 1999). Like many other commercial holothurian species, I. fuscus has been widely fished over the past decades to meet the growing demand for beche-de-mer in the major Asian markets (Castro 1994, Toral-Granda \& Martinez 2004). As the waters along mainland Ecuador became depleted, the fisheries shifted to the Galapagos Islands, raising international apprehension over the fate of this very unique marine reserve. In spite of worldwide concern, the Galapagos sea cucumber populations became the focus of intensive and poorly managed exploitation in the early 1990s. Since then, governmental attempts at regulating sea cucumber harvests, and banning them in some areas, have met strong opposition from local fisherman in Ecuador. Aquaculture and stock enhancement have been put forth as possible solutions to the current $I$. fuscus crisis (Fajardo-Leon \& Velez-Barajas 1996, GutierrezGarcia 1999). Captive breeding of the species was recently achieved (Hamel et al. 2003, Mercier et al. 2004) and it is expected eventually to provide part of the solution to the Galapagos sea cucumber fishery management.

In this context, understanding spawning periodicities and the factors that regulate them is not only important from an ecological standpoint but also for improved resource management. The present study therefore developed the dual goals of investigating the factors responsible for the patterns of gamete release in Isostichopus fuscus and examining the implications of these findings for prospective fisheries and aquaculture programs. The main questions were: (1) How closely does gamete release follow the monthly lunar cycle? (2) Can the timing and magnitude of gamete release be predicted for a given month and for the whole year? (3) What proportion of individuals from the same area will be involved in each spawning episode? (4) Is spawning periodicity affected by captivity? This investigation was conducted by monitoring the spawning behaviour of large quantities of freshly caught and captive specimens over several years. Data obtained in outdoor and indoor tanks, either submitted to or withheld from the influence of the moon and other environmental factors, were compared.

\section{MATERIALS AND METHODS}

Collection. All sea cucumbers Isostichopus fuscus were collected by scuba divers between 10 and $20 \mathrm{~m}$ at Punta Ayangue $\left(01^{\circ} 59^{\prime} 33^{\prime \prime} \mathrm{S}, 80^{\circ} 45^{\prime} 23^{\prime \prime} \mathrm{W}\right)$ and Anconcito $\left(02^{\circ} 19^{\prime} 60^{\prime \prime} \mathrm{S}, 80^{\circ} 52^{\prime} 60^{\prime \prime} \mathrm{W}\right)$ in the Guayas Province along the coast of Ecuador.

Preliminary study. Because the reproductive habits of Isostichopus fuscus were virtually unknown at the onset of this study in 2000, individuals were collected and observed on a regular basis to identify the period of spawning. Batches of 30 individuals were initially collected at intervals varying between 3 and $7 \mathrm{~d}$, and placed in $18 \mathrm{~m}^{2}$ outdoor tanks. Sea cucumbers were routinely observed for signs of spawning activity and the tanks were screened for the presence of gametes. After witnessing a natural spawning at sunset a few days after the new moon, sea cucumber samples were collected on a daily basis. Thermal shocks (Hamel et al. 2001, Mercier \& Hamel 2002) and addition of dry sperm were used in attempts to induce spawning every evening around dusk in freshly 
caught individuals, as well as in individuals that were collected $24 \mathrm{~h}$ and $2 \mathrm{wk}$ before. Other animals were left undisturbed. Several hundred sea cucumbers were thus monitored daily for a period of $6 \mathrm{mo}$. As the monthly lunar pattern became clear, sampling was restricted to more precise dates for the main study, which focused on the finer details of spawning behaviour and periodicity.

Experimental setup of main study. The main study spanned from January 2002 to November 2005. During that period, between 188 and 2013 adult sea cucumbers (10 to $19 \mathrm{~cm}$ contracted length) were collected nearly every month, typically 3 to $8 \mathrm{~d}$ before the expected spawning nights. They were evenly distributed in 2 to 5 round tanks $\left(18 \mathrm{~m}^{2}\right)$ at densities that varied between 4 and 15 ind. $\mathrm{m}^{-2}$ but were typically 4 to 6 ind. $\mathrm{m}^{-2}$, which corresponds to historical pristine densities in the field (Shepherd et al. 2004). The tanks were filled with ca. $60 \mathrm{~cm}$ of water and supplied with a flow of ca. $10000 \mathrm{l}$ $\mathrm{h}^{-1}$. The sea water supply was filtered through sand, stored in concrete reservoirs and chlorinated and restabilized (chlorine residues removed prior to use), thus minimizing the input of phytoplankton and other natural products. Water temperature was roughly constant between 22 and $24^{\circ} \mathrm{C}$. The tanks were filled with ca. $15 \mathrm{~cm}$ of sand and fibreglass plates covered with bacteria and benthic invertebrates (e.g. worms, crustaceans, molluscs, hydrozoans). They were exposed to naturally fluctuating light and photoperiod through large transparent fibreglass roofing. The sea cucumbers were fed twice daily by addition of a mix of dead phytoplankton, ground macrophytes and goat manure.

Monitoring of gamete release. The tanks holding the sea cucumbers were monitored on a daily basis as part of routine maintenance. On each expected spawning night, efforts were intensified: between 5 and 7 highly trained technicians maintained continuous surveillance of the behaviour of freshly collected sea cucumbers in all the tanks, starting ca. 30 to $45 \mathrm{~min}$ before sunset. No artificial induction was ever used. Individuals that were preparing to spawn were identified before gamete broadcast by their characteristic sweeping movements and the formation of a bulge under the gonopore. They were immediately isolated in individual tanks as part of a larval rearing study (Hamel et al. 2003, Mercier et al. 2004). The time of gamete release was noted for each individual. This protocol was repeated on consecutive evenings until no sign of spawning was recorded. Unlike other species that are sensitive to manipulation (Battaglene et al. 2002), Isostichopus fuscus could be touched without interrupting gamete release in $>95 \%$ of cases. Data for cloud cover, sunset and moonrise were obtained from Weather Underground (www.wunderground.com) for the nearest village (Manta).
Tanks harbouring sea cucumbers from previous monthly collections were also monitored for signs of spawning; this was done nearly daily, either by visual inspection of the animals or screening the tanks for the presence of gametes. Additionally, for a period of 3 mo in 2002 (May, June, July), some freshly collected individuals ( $\mathrm{n}=279,479,573$, respectively) were placed in tanks of similar volume and water flow but within an enclosure that blocked external light. Their spawning activity was monitored as described above. These individuals were subsequently returned to conditions of naturally fluctuating light and inspected as usual.

Gametogenic cycle. Between January and September 2002, gametogenic stages were studied every month in non-spawners (ca. 10 females and 10 males) using qualitative inspection of the gonad and microscopic observation of gamete maturity ratios. Based on a classification used in previous work (Hamel et al. 1993, Mercier \& Hamel 2002, Drumm \& Loneragan 2005), female gametogenic maturity was categorized as: (1) post-spawning (i.e. thin convoluted gonadal tubules, with residual mature oocytes in scattered pockets and presence of nutritive phagocytes), (2) growth (i.e. medium tubule diameter, large quantity of oogonia and small primary oocytes), (3) mature (i.e. highly stretched tubules with thin epithelium, completely or nearly filled with large vitellogenic oocytes). A similar characterisation was used for males: (1) postspawning (i.e. thin convoluted gonadal tubules with residual mature spermatozoa still visible in scattered pockets), (2) growth (i.e. medium tubule diameter, large quantity of spermatogonia and spermatocytes), (3) mature (i.e. highly stretched tubule with thin epithelium, completely or nearly filled with spermatozoa).

\section{RESULTS}

The preliminary study of Isostichopus fuscus revealed that: (1) individuals never spawned, either naturally or after artificial induction, except in the few days following the new moon; (2) during that particular lunar phase, both freshly caught and captive individuals maintained in different tanks released their gametes; (3) spawning was restricted to a portion of the population and always started around sunset.

During the main study, the monthly spawning activity of Isostichopus fuscus was monitored during $31 \mathrm{mo}$ over a 4 yr period. Spawning consistently took place 1 to $4 \mathrm{~d}$ after the new moon (Table 1). A complete set of monthly data was recorded in 2002, which served for the more refined analysis of the annual cycle.

According to the 2002 data, a proportion of male and/or female Isostichopus fuscus spawned every month, with an annual peak occurring in April when 
Table 1. Isostichopus fuscus. Spawning patterns. nd: not determined

\begin{tabular}{|c|c|c|c|c|c|c|c|c|c|}
\hline \multirow[t]{2}{*}{ Year } & \multirow[t]{2}{*}{ Month } & \multicolumn{4}{|c|}{$\begin{array}{l}\text { Total (N) No. of individuals } \\
- \text { Spawning }\end{array}$} & \multicolumn{4}{|c|}{$\begin{array}{l}\text { Spawning date } \\
\text { Days after the new moon }\end{array}$} \\
\hline & & & $\sigma^{\prime \prime}$ & ф & $\%$ & 1 & 2 & 3 & 4 \\
\hline \multirow[t]{12}{*}{2002} & January & 400 & 28 & 19 & 11.8 & $0^{7}$ & $0^{7} \mathrm{Q}$ & $0^{7} 0$ & \\
\hline & February & 188 & 13 & 10 & 12.2 & & $0^{1} \quad \begin{array}{l}7 \\
\end{array}$ & $0^{7} \stackrel{7}{9}$ & $0^{7} \circ$ \\
\hline & March & 444 & 52 & 27 & 17.8 & & $0^{7}$ & $0^{7} \stackrel{7}{9}$ & $0^{7} \stackrel{7}{7}$ \\
\hline & April & 375 & 90 & 41 & 34.9 & & $0^{7}$ & $0^{17} 0^{+}$ & \\
\hline & May & 279 & 10 & 1 & 3.9 & & $0^{7}$ & $0^{7}=$ & \\
\hline & June & 297 & 15 & 8 & 7.7 & & & $0^{7} \stackrel{7}{9}$ & $0^{7}$ ㅇ \\
\hline & July & 573 & 4 & 0 & 0.7 & & $0^{1}$ & $0^{7}$ & \\
\hline & August & 597 & 28 & 12 & 6.7 & & $0^{1} \circ$ & $0^{1} \circ$ & \\
\hline & September & 410 & 32 & 12 & 10.7 & & & $0^{7}$ & $0^{11}$ 우 \\
\hline & October & 356 & 27 & 14 & 11.5 & $0^{11} \circ$ & $0^{1} 0$ & & \\
\hline & November & 408 & 39 & 16 & 13.5 & $0^{7} 0^{7}$ & $0^{11}+\frac{7}{9}$ & $0^{\prime \prime} \circ$ & \\
\hline & December & 485 & 35 & 16 & 10.5 & $0^{7}$ & $0^{7}$ & $0^{11}+\frac{7}{+}$ & \\
\hline \multirow[t]{4}{*}{2003} & January & 385 & 61 & 10 & 2.6 & & & $0^{11} \circ$ & \\
\hline & April & 440 & 11 & 8 & 1.82 & & $0^{7} 0$ & & \\
\hline & June & nd & nd & 20 & nd & & & $0^{11} \circ$ & \\
\hline & October & 478 & 122 & 51 & 10.7 & $0^{1}$ & $0^{1} \circ$ & $0^{11}+\frac{7}{9}$ & \\
\hline \multirow[t]{5}{*}{2004} & January & 944 & nd & 24 & 2.5 & & & $0^{7} \circ$ & $0^{7}$ \% \\
\hline & April & 793 & 52 & 6 & 0.8 & $0^{1}$ & $0^{\prime \prime} \circ$ & $0^{7} \stackrel{7}{9}$ & $0^{11} \stackrel{7}{9}$ \\
\hline & May & 19 & 105 & 34 & 4.2 & $0^{1}$ & $0^{11} 0^{7}$ & $0^{17} 0^{7}$ & \\
\hline & June & 773 & 53 & 24 & 3.1 & $0^{7}$ & $0^{7} 0^{7}$ & $0^{7} \stackrel{7}{9}$ & \\
\hline & November & nd & 117 & 50 & nd & & $0^{11} \stackrel{+}{9}$ & $0^{x} \stackrel{+}{+}$ & \\
\hline \multirow[t]{10}{*}{2005} & January & 642 & 71 & 7 & 1.1 & $0^{7}$ & $0^{11} \circ$ & $0^{11} \div$ & $0^{11} \%$ \\
\hline & February & 2013 & 197 & 73 & 3.6 & $0^{3}$ 웅 & $0^{11}+\frac{7}{9}$ & $0^{7} \stackrel{7}{9}$ & \\
\hline & March & 755 & 99 & 18 & 2.4 & $\begin{array}{ll}1 & 7 \\
0 & 0\end{array}$ & $0^{11}+9$ & $\begin{array}{ll}1 & 7 \\
0^{1} & +\end{array}$ & $0^{11}+$ \\
\hline & April & 1163 & 92 & 12 & 1.0 & $\begin{array}{ll}7 \\
0^{1} & 7 \\
\end{array}$ & $0^{11}+\frac{7}{+}$ & $0^{11}+7$ & $0^{11} \stackrel{7}{q}$ \\
\hline & May & 873 & 74 & 24 & 2.8 & $0^{7}{ }^{7}$ & $0^{1} \stackrel{7}{9}$ & & \\
\hline & June & 393 & 62 & 36 & 9.6 & $0^{7}$ & $0^{11}$ 웅 & $0^{\prime \prime} \circ$ & $0^{11} \circ$ \\
\hline & July & 477 & 39 & 22 & 4.6 & $0^{1}$ & $0^{11}+\frac{7}{9}$ & $0^{7} \stackrel{7}{9}$ & $0^{11} \stackrel{7}{9}$ \\
\hline & August & 658 & 145 & 75 & 11.4 & $0^{1}$ & $0^{1} \stackrel{7}{9}$ & $0^{7} \stackrel{7}{9}$ & $0^{11} \stackrel{7}{9}$ \\
\hline & October & 1354 & 216 & 58 & 4.3 & $0^{1}$ ㅇ & $0^{7} \stackrel{7}{9}$ & & \\
\hline & November & 1404 & 74 & 52 & 3.7 & $0^{11} \stackrel{+}{+}$ & $0^{11} \stackrel{+}{+}$ & & \\
\hline \multicolumn{6}{|c|}{ Total number of spawnings } & 18 & 26 & 26 & 12 \\
\hline \multicolumn{6}{|c|}{ Total number of $0^{7}$ only spawnings } & 10 & 5 & 2 & 0 \\
\hline
\end{tabular}

$34.9 \%$ of individuals spawned, of which $68.7 \%$ were males and $31.3 \%$ were females (Table 1, Fig. 1). The lowest activity was recorded between May and August, when only 0.7 to $7.7 \%$ of individuals released gametes (Table 1). Statistical results revealed that the number of spawning individuals was significantly lower between May and August than during the rest of the year (Kruskal-Wallis, $\mathrm{p}<0.05$ ). Comparison with partial data obtained in subsequent years revealed a degree of variability in the relative abundance of spawning individuals recorded every month (Table 1). The 10 mo data set of 2005 showed that peak activity occurred in August when $33.4 \%$ of individuals engaged in spawning, even though the data showed a much more even trend than in 2002, with no major peak. The 2002 and 2005 annual spawning averages were not significantly different at $11.8 \pm 8.5 \%$ and $16.1 \pm 7.9 \%$, respectively (mean $\left.\pm \mathrm{SD} ; \chi^{2}, \mathrm{p}>0.05\right)$. When combining the 31 monthly observations of this study, the overall average proportion of spawning individuals was $14.2 \pm 8.9 \%$.

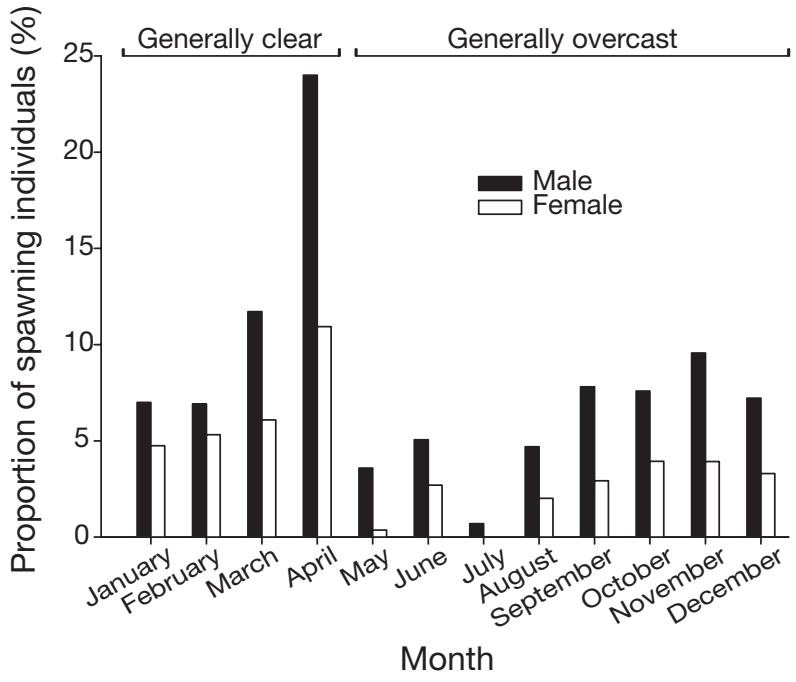

Fig. 1. Isostichopus fuscus. Proportion of total male and female adults spawning each month between January and December 2002. Weather patterns indicated above histograms 


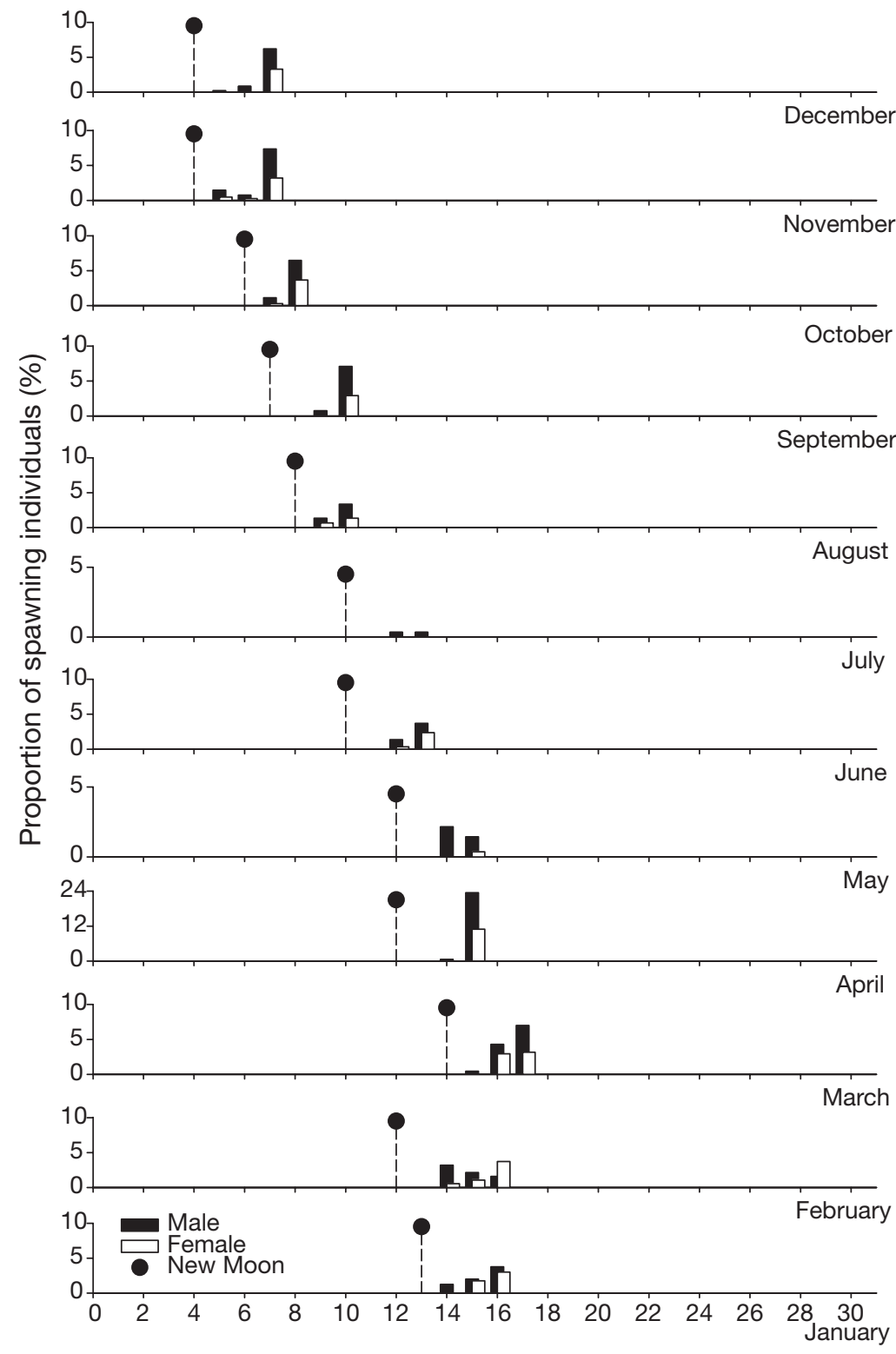

Fig. 2. Isostichopus fuscus. Proportion of spawning males and females correlated with the lunar cycle between January and December 2002. Note variable scale of $y$-axes

Monthly spawning always occurred within 1 to $4 \mathrm{~d}$ after the new moon (Table 1). In 2002, evidence of gamete release was noted on 2 consecutive evenings between April and October and on 3 consecutive evenings during the remaining period. However, peak spawning activity was clearly restricted to 1 evening on $41.7 \%$ of occasions, and was most often recorded on the second or third night after the new moon (Table 1, Fig. 2). Spawning patterns recorded in subsequent years were less consistent, with spawning observed on 1 to 4 consecutive evenings (Table 1 ). These results were interpreted cautiously due to a lower level of con- trol and accuracy during data collection. A constant trend was that in spite of a sex ratio of roughly $1: 1$, as previously observed for this species (Herrero-Pérezrul et al. 1999), males always formed the largest fraction of the spawning population in 2002 (71.2 \pm $12.4 \%$; mean $\pm \mathrm{SD}_{i} \mathrm{n}=12$ ) and in combined spawning accounts $(73.1 \pm$ $11.5 \% ; \mathrm{n}=31$ ). Incidentally, some males were observed to spawn alone on certain nights, whereas females never were (Fig. 1, Table 1).

Individuals maintained in captivity for several months displayed the same lunar pattern; they were never observed to spawn at any other time of the month than after the new moon and they spawned predominantly on the same evening(s). Conversely, individuals maintained in tanks that were not exposed to moonlight did not display any spawning activity until they were again submitted to lunar-phase fluctuations.

Based on the 2002 data, males consistently spawned first, at or near sunset, whereas in most months females started spawning around or after the peak in male spawning (Fig. 3). No correlation with time of moonrise was observed for either sex (1-way ANOVA, $p>0.05)$. Gamete release was spread over a significantly shorter period in females than in males (Student's $t$-test, $\mathrm{p}=0.009$ ), with respective spawning activity lasting $48 \pm 18 \mathrm{~min}$ $($ mean $\pm \mathrm{SD}, \mathrm{n}=21)$ and $62 \pm 18 \mathrm{~min}(\mathrm{n}=$ 27) (Fig. 3). The shortest spawning events occurred between May and July when lower proportions of individuals were engaged in spawning activity (Table 1, Fig. 3). Indeed, male spawning duration was significantly shorter in May-July compared with January-April and August-December (1way ANOVA, $p=0.015$ ). Female spawning duration for the same period was difficult to compare because only 1 female spawned in May and none spawned in July (Table 1). Fig. 4 illustrates the finer details of the main spawning of April 15, 2002, which involved 90 males and 41 females, encompassing nearly $35 \%$ of the population. The first male spawned at 18:20 h, $5 \mathrm{~min}$ before sunset, progressively followed by other males within the next $5 \mathrm{~min}$. Spawning activity peaked around 18:40 h, when 17 males were reported to 


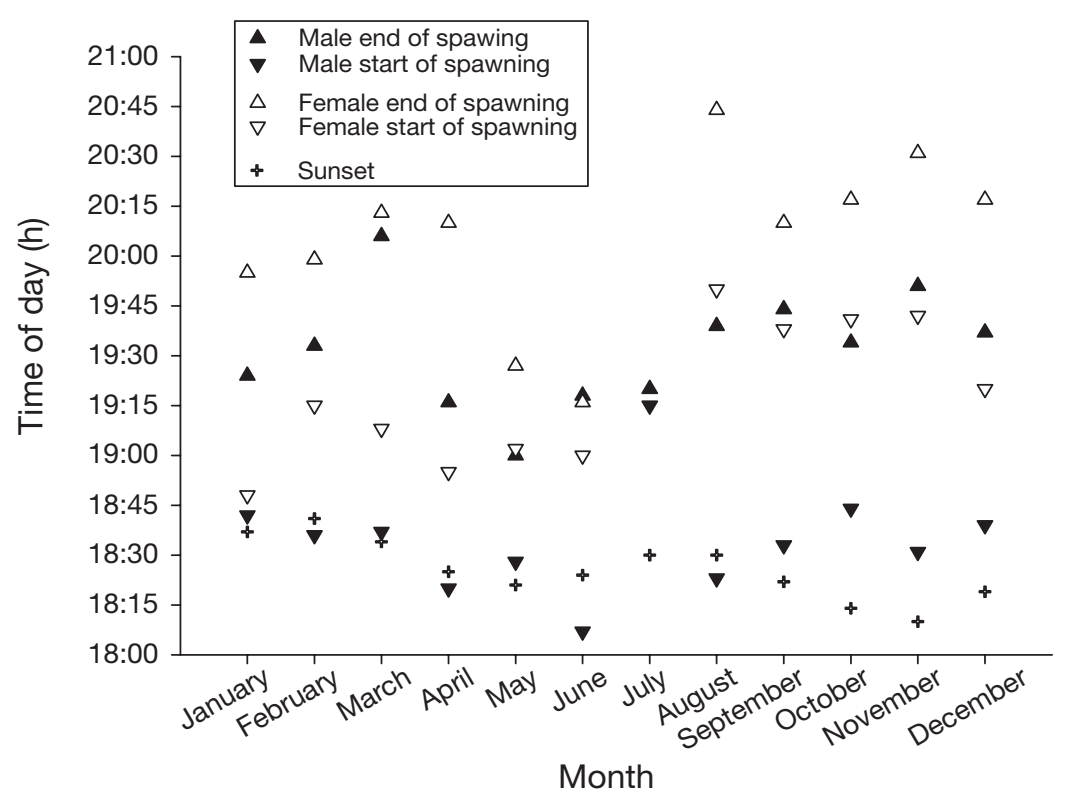

Fig. 3. Isostichopus fuscus. Average start and end time of gamete release for males and females during monthly spawning in 2002

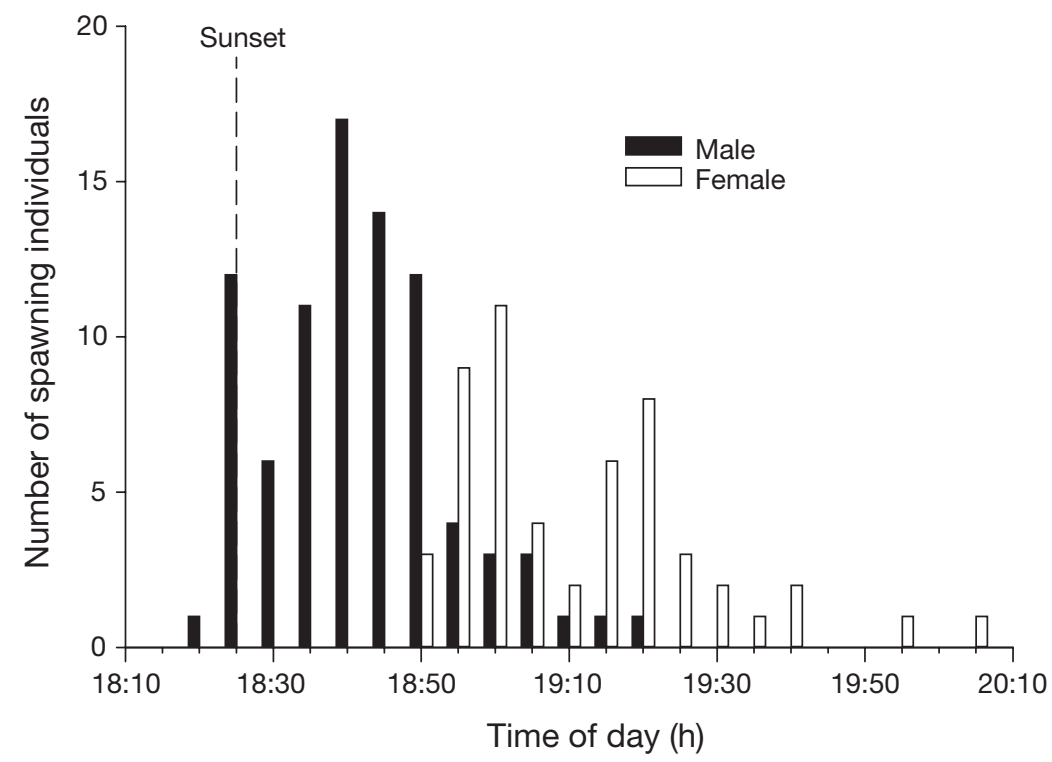

Fig. 4. Isostichopus fuscus. April 15, 2002 spawning event, showing no. of males and females releasing gametes over time

spawn, followed by a gradual decrease and a final spawning noted at 19:20 h (Fig. 4). Females initiated gamete release at $18: 50 \mathrm{~h}$, shortly after the male peak spawning; 2 consecutive peaks were recorded (i.e. 19:00 and 19:20 h), and the last spawning occurred at 20:05 h (Fig. 4). This pattern is consistent with most of the 31 monthly spawning events observed in this study. Note that individual gamete release by Isostichopus fuscus is brief, usually limited to one or several 'spurts' .
There is a clearly marked seasonal cycle in Ecuador: outside El Niño events, the climate along the coast is roughly divided into 2 main seasons. January to April is the rainy season, with higher daytime temperatures and frequent heavy rains but generally clear skies. The dry season that extends from May to December is cooler, with almost no rain but typically damp and overcast weather. The year 2002 followed this general pattern. Although no significant difference was noted in the proportion of spawning males between the rainy and dry seasons, the proportion of spawning females was greater in the January-April interval than in May-December $\left(\chi^{2}, p=0.005\right)$. Furthermore, in the months of May, August and October, which were particularly overcast, females started spawning only after male spawning was completed (Fig. 3).

At least a portion of individuals spawned in a given month (Table 1), and investigation of the gonadal development in non-spawning males and females revealed the absence of any clear annual or monthly trend in gametogenesis. From January to September 2002, all 3 stages of gonadal development (i.e. post-spawning, growth, mature) were identified in the monthly samples, except in August when no mature males were detected (Fig. 5).

\section{DISCUSSION}

The present study ascertained the spawning pattern of Isostichopus fuscus in Ecuador by monitoring gamete release over several years. Our results reveal a highly predictable spawning periodicity attuned with the lunar cycle and further refined by a strong diel component. Part of the population consistently spawned around sunset, 1 to $4 \mathrm{~d}$ after the new moon, both in freshly caught individuals and in those that had been maintained in captivity for months. Individuals kept in tanks that were shaded from the moonlight did not spawn until they were again exposed to the day/night cycle. Furthermore, spawning of $I$. fuscus was monitored in tanks that were not submitted to any tidal oscillation and were maintained under constant 


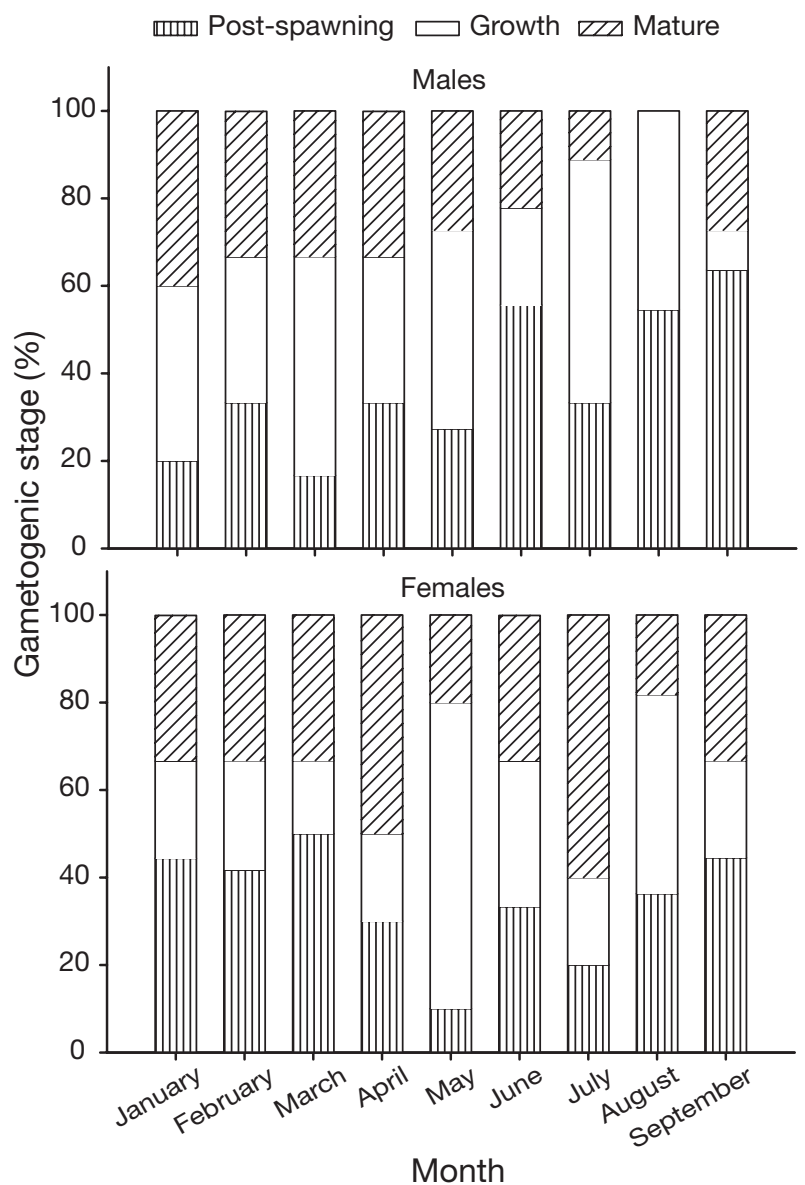

Fig. 5. Isostichopus fuscus. Proportion of different gametogenic stages observed in the gonads of non-spawning males and females between January and September $2002(n=9$ to 12)

temperature and salinity conditions, clearly marking lunar luminance as the major influence.

Many marine invertebrates are believed to display a lunar reproductive cycle as a means of increasing fertilization success (Omori 1995); however, thorough documentation is still rare. Evidence of spawning occurring a few days before or after specific lunar phases was reported in echinoderms (Pearse 1975, Kubota 1981, 2000, Babcock et al. 1992, Mercier et al. 2000, Coppard \& Campbell 2005) and other marine invertebrates (e.g. Caspers 1984, Jokiel et al. 1985, Babcock et al. 1986, Giese \& Kanatani 1987, Harrison \& Wallace 1990, Pearse 1990, Szmant 1991, Morgan 1995, Tanner 1996, McGuire 1998, Watson et al. 2000, Andries 2001, Bentley et al. 2001). However, there are very few accounts of a predictable, synchronous and epidemic spawning pattern such as that presented here. Among echinoderms, only the crinoid Oxycomanthus japonicus has been shown to release gametes in a predictable way on a given lunar phase, once a year (Kubota 1981). A similar pattern was recently described for an apodid sea cucumber (Kubota 2000).

Within the larger group of marine invertebrates, predictable spawning events with lunar components are often restricted to annual peaks associated with water temperature. Examples include the swarming of marine polychaetes (Andries 2001, Bentley et al. 2001) and the tide-influenced breeding of tropical abalones (Counihan et al. 2001). Another classic case is the epidemic spawning of corals. On the Great Barrier Reef in Australia, the majority of coral species broadcastspawn gametes annually, during the week following the full moon in the austral spring (Richmond \& Hunter 1990). As for brooding corals, they usually release planula larvae for several days with maxima around the new moon or the full moon depending on species or specific 'types', mostly around one annual peak period (Harrison \& Wallace 1990). Furthermore, members of the Montastraea annularis species complex from Panama and the Bahamas were observed to spawn after sunset 4 to $8 \mathrm{~d}$ following the full moon between August and October, both in the field and in the laboratory (Levitan et al. 2004). These findings are consistent with previous reports throughout the Caribbean (Levitan et al. 2004).

In spite of their prevalence, ultimate and even proximate causes of lunar rhythms have not been entirely identified, because studies are either too short or focus mainly on indirect evidence (e.g. histology, GSI). Indeed, aside from a few observations in the field (e.g. Levitan 1988, Pearse et al. 1988, Lamare \& Stewart 1998), most previous studies of spawning in echinoderms assessed the timing of reproduction based on gonadal indices or gamete maturity (Giese et al. 1991, Coppard \& Campbell 2005). Direct evidence (i.e. gamete release) of monthly spawning attuned to lunar phases has to our knowledge not been documented, with the exception of a 4-mo set of data from the sea cucumber Holothuria scabra (Mercier et al. 2000).

Many diademid sea urchins display monthly lunar periodicities in their breeding, but positive correlations were generally obtained from gonad indices (Coppard \& Campbell 2005). Observations of spawning in the field seems to tell a different story: unlike spawning observations of Isostichopus fuscus and contrary to gametogenic evidence, gamete shedding in Diadema antillarium was scattered over the month even if more common around the new moon (Levitan 1988). Such data emphasize the fact that lunar periodicity in gametogenesis may not necessarily equate to distinct lunar periodicity in gamete release. Interestingly, gametogenesis of $I$. fuscus did not reveal any obvious monthly trend and could have been misinterpreted as an indication of poorly synchronized spawning activity. Studies of chronobiology are further limited by our 
incomplete understanding of how the multiple environmental cycles can, alone or in combination, produce specific temporal patterns. Two consistent levels of synchrony were observed in this study: monthly (lunar periodicity) and daily (gamete release around sunset). As is often the case (Bentley et al. 2001, Naylor 2001), a hierarchy of exogenous signals must therefore be helping to synchronize the reproduction of I. fuscus.

Cyclic processes similar to that observed in the present study can either be driven directly by a rhythmic change in the environment or involve the action of an internal biological clock regulated by external stimuli. Spawning activity in Isostichopus fuscus occurred without any tidal influence but was not retained in the absence of moonlight, inferring that its periodicity is under the influence of lunar irradiance and is not freerunning, unlike that observed in abalone (Counihan et al. 2001), lugworms (Howie 1984) and other marine worms (Bentley et al. 2001). In I. fuscus, it appears that the luminous intensity of the moon cannot be defined as a Zeitgeber that regulates a biological clock, but rather as a direct trigger. Planulation of some coral species is also directly correlated with the night irradiance (moonlight); however, the role of endogenous rhythms is not always clear. Jokiel et al. (1985) demonstrated that timing of larval release by Pocillopora damicornis can be modified by artificially manipulating the nocturnal light provided to colonies: peak production tends to shift to follow the usual lunar phase. The same authors found that colonies submitted to constant darkness or constant light quickly lost synchronisation of monthly planulation. McGuire (1998) also suggested that Porites astreoides corals maintained in captivity did not persist with monthly larval release; he postulated that this was due to interference by city lighting with natural night-time irradiance. Although cloud cover during overcast months seemed to impact on spawning of female I. fuscus in the 2002 cycle, it did not entirely prevent spawning activity nor influence male gamete release. This might be due to the fact that nightly variations in lunar luminance can still be registered, especially because the cue is set around the new moon. Evidence of sensitivity to moonlight has been documented in marine animals. Gorbunov \& Falkowski (2002) showed that coral polyps can sense the blue portion of lunar irradiance, and Takemura et al. (2004) found that rabbitfish exhibited changes in plasma melatonin levels in response to moonlight intensity. Furthermore, a model of the interplay between environmental factors and the endocrine mechanisms that control spawning induction in lugworms was recently proposed (Watson et al. 2000). It is therefore entirely possible that $I$. fuscus can sense minute variations in nocturnal light and react to them, possibly through shifts in hormone levels. The same could be true for the perception of diel light variations at sunset.

The rather low proportion of Isostichopus fuscus involved in monthly spawning events $(<35 \%)$ and the high variability in gametogenic development of nonspawners support the hypothesis that only part of the population releases gametes on a monthly basis, and that different individuals spawn every month. A full set of mature gonads apparently takes more than a lunar cycle to be developed. This is emphasised by the recurrent observation of post-spawned and fully mature gonads among non-spawners, suggesting that some individuals had spawned only the month before and that others would be ready by the following lunar phase. The data gathered in the present study seem to support a variant of the theory of gated rhythms proposed by Olive (1984): individuals that reach a state of readiness within a certain 'window of opportunity' - within a given period of the month in the case of I. fuscus - will proceed towards reproduction in that period. Based on histological samples and a review of the literature, Pearse (1968) similarly concluded that gametogenesis was asynchronous in several echinoderm species living near the equator, and that part of their population was thus reproductive year-round. However, he found no evidence of lunar periodicities. A previous histological study of an I. fuscus population from the Gulf of California $\left(24^{\circ} 35^{\prime} \mathrm{N}, 110^{\circ} 15^{\prime} \mathrm{W}\right)$ suggested that the reproductive season, characterized by partial spawning events, spanned between July and September during peak sea surface temperatures (Herrero-Pérezrul et al. 1999). This spawning scheme is not entirely consistent with that of the present study, possibly because of the method used; however, a similar latitudinal variation in the frequency of gamete release was proposed for other species of holothurians (Mercier et al. 2000). The rather constant pattern of seawater temperature around the equator may explain the limited role played by this factor in the reproductive periodicity of I. fuscus from Ecuador. Nevertheless, this and other environmental parameters are likely to influence the annual or monthly reproductive output, suggesting that further studies should be conducted, which might also include measures of air pressure and air temperature.

The ecological role of lunar periodicities has been the subject of many discussions. Two main streams of thought stand out: those of adult-biology hypotheses and hatchling-biology hypotheses. The latter is particularly relevant to intertidal invertebrates, in which tidal or semi-lunar periodicities are said to maximize the survival and settlement of planktonic larvae/juveniles (Pearse 1990, Morgan 1995). However, lunar spawning rhythms of tropical or equatorial species submitted to 
very small tidal amplitudes are less likely to be related to larval dispersal. Advantages to adults, through synchronized spawning aggregations or migrations and defence against predators, have largely centered on fishes (Robertson et al. 1990). In the case of Isostichopus fuscus, it can be argued that eggs released near the new moon would be concealed by the relative darkness and attract fewer visual predators. But the most likely benefit of lunar spawning periodicity to I. fuscus and other marine invertebrates may be to optimize fertilization success, even though difficulties with this hypothesis have been outlined (Pearse 1990). The fine coordination of spawning around sunset, and the slight asynchrony between male and female gamete release, are even more important in this context. The benefits of male-first spawning have been examined in another broadcast spawning echinoderm and discussed by Levitan (2005). Although fertilization rates were not measured during the present study, there is a clear advantage to this strategy: females always spawned in fewer numbers but they mostly did so at the time of peak male spawning, when spermatozoa concentrations were presumably optimal. Incidentally, developing embryos were often found in the tanks, indicating that the spawning patterns could result in successful fertilization (albeit in a confined, flow-through system). Although the overall duration of sperm release was longer than the duration of egg release, it should be noted that I. fuscus males typically emit sperm in a few strong bursts over a short period, possibly placing the earlyspawning individuals at a disadvantage in terms of sperm competition (Levitan 2005). It would thus be interesting to further investigate the strategy behind this fine-scale asynchrony in terms of sexual selection.

Like other aspects of chronobiology, lunar periodicity also has considerable implications for a variety of applied marine sciences, including management of fisheries, aquaculture and resource management programs. Stock assessments for the sustainable management of fisheries require a good understanding of the predictability of spawning events as well as knowledge of larval development and settlement. The fact that Isostichopus fuscus can reach densities of 0.8 to 6.2 ind. $\mathrm{m}^{-2}$ in pristine areas (Shepherd et al. 2004), combined with partial monthly spawning that occurs in nearly perfect synchrony, seems to predispose them to a high fertilization success. Some recruitment is expected to occur year-round in populations from around the equator, therefore spreading reproductive effort and maximizing recruitment. However, dispersal of planktonic larvae by currents must be taken into account when considering the sustainability of the resource. This becomes especially important in cases where specific populations (e.g. around the Galapagos Islands) may eventually benefit from protective measures: the positive impact on recruitment may not necessarily be observed locally. Furthermore, heavy harvests could still decrease the reproductive capability and potential monthly recruitment of I. fuscus by bringing population densities below the reproductive threshold. Concern over the rapidly depleting stocks of I. fuscus in the Galapagos marine reserve was recently expressed (Toral-Granda \& Martinez 2004).

Predictable monthly spawning patterns are an important tool for aquaculture as well, as they make the use of spawning induction techniques unnecessary and ensure a constant supply of naturally spawned gametes, which are presumably healthier than their artificially obtained counterparts. Captive breeding of Isostichopus fuscus has indeed benefited from a good understanding of the species' lunar spawning periodicity (Mercier et al. 2004). Juveniles can now be reared year-round on a monthly basis. The fact that captive individuals retain their spawning patterns when exposed to the natural day/night cycle is another advantage of the species. Taking it a step further toward stock replenishment is a possible avenue, even though many other ecological variables would need to be investigated before introducing captive-bred specimens into the potentially vulnerable habitats of coastal Ecuador and the Galapagos Islands.

This study of Isostichopus fuscus provides one of the clearest and most reliable examples of lunar spawning periodicity to date. Along the coast of Ecuador, this species releases gametes every new moon around sunset, with peak activity possibly occurring during periods of clearer weather. Monthly spawning is under the influence of lunar luminance; it involves only part of the population, promoting the occurrence of recruitment throughout the year. In order to complement the results presented here, future research should focus on: (1) gathering data of gamete release in the field, (2) investigating variations in spawning patterns and level of synchrony within and between populations and individuals, (3) assessing sensitivity to moonlight, including detection pathways, and (4) testing spawning induction by artificial lunar cycles.

Acknowledgements. We acknowledge the support of technical staff at IEA, without whom this study could not have been performed. We also thank N. Hidalgo for his assistance with the data compilation, and D. Levitan and 2 anonymous referees for valuable comments.

\section{LITERATURE CITED}

Andries JC (2001) Endocrine and environmental control of reproduction in Polychaeta. Can J Zool 79:254-270

Babcock RC, Bull GD, Harrison PL, Heyward AJ, Oliver JK, Wallace CC, Willis BL (1986) Synchronous spawnings of 
105 scleractinian coral species on the Great Barrier Reef. Mar Biol 90:379-381

Babcock RC, Mundy C, Keesing J, Oliver J (1992) Predictable and unpredictable spawning events: in situ behavioural data from free spawning coral reef invertebrates. Invertebr Reprod Dev 22:213-228

Battaglene SC, Seymour EJ, Ramofafia C, Lane I (2002) Spawning induction of three tropical sea cucumbers, Holothuria scabra, H. fuscogilva and Actinopyga mauritiana. Aquaculture 207:29-47

Bentley MG, Olive PJW, Last K (2001) Sexual satellites, moonlight and the nuptial dances of worms: the influence of the moon on the reproduction of marine animals. Earth Moon Planets 85-86:67-84

Caspers H (1984) Spawning periodicity and habitat of the palolo worm Eunice viridis (Polychaeta: Eunicidae) in the Samoan Islands. Mar Biol 79:229-236

Castro LRS (1994) The fishery of the sea cucumbers Isostichopus fuscus and Parastichopus parvimensis in Baja California, Mexico. In: David B, Guille A, Féral JP, Roux M (eds) Echinoderms through time. Balkema, Rotterdam, p 504

Counihan RT, McNamara DC, Souter DC, Jebreen EJ, Preston NP, Johnson CR, Degnan BM (2001) Pattern, synchrony and predictability of spawning of the tropical abalone Haliotis asinina from Heron Reef, Australia. Mar Ecol Prog Ser 213:193-202

Coppard SE, Campbell AC (2005) The lunar periodicity of diadematid echinoids breeding in Fiji. Coral Reefs 24: 324-332

Drumm DJ, Loneragan NR (2005) Reproductive biology of Holothuria leucospilota in the Cook Islands and the implications of traditional fishing of gonads on the population. N Z J Mar Freshw 39:141-156

Fajardo-Leon MC, Velez-Barajas A (1996) Pesqueneria de pepino de mar. In: Casas-Valdez M, Ponce Diaz G (eds) Estudia del potencial pesquero y acuicola de Baja California Sur, Vol 2. SEMARNAP and CICIMAR, La Paz, p 151-165

Giese AC, Kanatani H (1987) Maturation and spawning. In: Giese AC, Pearse JS, Pearse VB (eds) Reproduction of marine invertebrates, Vol IX. Blackwell Scientific, Palo Alto, CA, p 252-313

Giese AC, Pearse JS, Pearse VB (1991) Reproduction of marine invertebrates, Vol VI. Echinoderms and Lophophorates. The Boxwood Press, Pacific Grove, CA

Gorbunov MY, Falkowski PG (2002) Photoreceptors in the cnidarian hosts allow symbiotic corals to sense blue moonlight. Limnol Oceanogr 47:309-315

Gutierrez-Garcia A (1999) Potential culture of sea cucumber in Mexico. SPC Beche-de-Mer Inf Bull 11:26-29

Hamel JF, Himmelman JH, Dufresne L (1993) Gametogenesis and spawning of the sea cucumber Psolus fabricii (Duben and Koren). Biol Bull (Woods Hole) 184:125-143

Hamel JF, Conand C, Pawson D, Mercier A (2001) The sea cucumber Holothuria scabra (Holothuroidea: Echinodermata): its biology and its exploitation as beche-de-mer. Adv Mar Biol 41:129-223

Hamel JF, Ycaza RH, Mercier A (2003) Larval development and juvenile growth of the Galapagos sea cucumber Isostichopus fuscus. SPC Beche-de-Mer Inf Bull 18:3-8

Harrison PL, Wallace CC (1990) Reproduction, dispersal and recruitment of scleractinian corals. In: Dubinsky Z (ed) Ecosystems of the world, Vol 25. Coral reefs. Elsevier, Amsterdam, p 133-207

Herrero-Pérezrul MD, Reyes Bonilla H, Garcia-Dominguez F, Cintra-Buenrostro CE (1999) Reproduction and growth of Isostichopus fuscus (Echinodermata: Holothuroidea) in the
Southern Gulf of California, Mexico. Mar Biol 135: $521-532$

Howie DID (1984) The reproductive biology of the lugworm Arenicola marina L. Forts Zool 29:247-263

Jokiel PL, Ito RY, Liu PM (1985) Night irradiance and synchronization of lunar release of planula larvae, in the reef coral Pocillopora damicornis. Mar Biol 88:167-174

Kubota H (1981) Synchronisation of spawning in the crinoid, Comanthus japonica. In: Clark WH, Adams TS (eds) Advances in invertebrate reproduction (developments in endocrinology). Elsevier, Amsterdam, p 69-74

Kubota T (2000) Reproduction of the apodid sea cucumber Patinapta ooplax: semilunar spawning cycle and sex change. Zool Sci 17:75-81

Lamare MD, Stewart BG (1998) Mass spawning by the sea urchin Evechinus chloroticus (Echinodermata: Echinoidea) in a New Zealand fjord. Mar Biol 132:135-140

Levitan DR (1988) Asynchronous spawning and aggregative behavior in the sea urchin Diadema antillarum (Philippi). In: Burke RD, Mladenov PV, Lambert P, Parsley RL (eds) Echinoderm biology: Proc 6th Int Echinoderm Conf. Balkema, Rotterdam, p 181-186

Levitan DR (1995) The ecology of fertilization in free-spawning invertebrates. In: McEdward LR (ed) Ecology of marine invertebrate larvae. CRC Press, Boca Raton, FL, p 123-156

Levitan DR (2005) Sex specific spawning behavior and its consequences in an external fertilizer. Am Nat 165: 682-694

Levitan D, Fukami H, Jara J, Kline D, McGovern T, McGhee K, Swanson C, Knowlton N (2004) Mechanisms of reproductive isolation among sympatric broadcast-spawning corals. Evolution 58:308-323

McGuire MP (1998) Timing of larval release by Porites astreoides in the northern Florida Keys. Coral Reefs 17: $369-375$

Mercier A, Hamel JF (2002) Perivisceral coelomic fluid as a mediator of spawning induction in tropical holothurians. Invert Reprod Dev 41:223-234

Mercier A, Battaglene SC, Hamel JF (2000) Periodic movement, recruitment and size related distribution of sea cucumbers Holothuria scabra in the Solomon Islands. Hydrobiologia 440:81-100

Mercier A, Ycaza RH, Hamel JF (2004) Aquaculture of the Galapagos sea cucumber, Isostichopus fuscus. In: Lovatelli A, Conand C, Purcell S, Uthicke S, Hamel JF, Mercier A (eds) Advances in sea cucumber aquaculture and management. FAO Fish Tech Pap No. 463. FAO, Rome, p 347-358

Morgan SG (1995) The timing of larval release. In: McEdward LR (ed) Ecology of marine invertebrate larvae. CRC Press, Boca Raton, FL, p 157-191

Naylor E (2001) Marine animal behaviour in relation to lunar phase. Earth Moon Planets 85-86:291-302

Olive PJ (1984) Environmental control of reproduction in Polychaeta. Forts Zool 29:17-38

Omori K (1995) The adaptative significance of a lunar or semilunar reproductive cycle in marine animals. Ecol Model 82:41-49

Pearse JS (1968) Patterns of reproductive periodicities in four species of Indo-Pacific echinoderms. Proc Indian Acad Sci B 67:247-279

Pearse JS (1975) Lunar reproductive rhythms in sea urchins: a review. J Interdiscip Cycle Res 6:47-52

Pearse JS (1990) Lunar reproductive rhythms in marine invertebrates: maximizing fertilization? In: Hosin M, Yamashita $\mathrm{O}$ (eds) Advances in invertebrate reproduction. Elsevier, Oxford, p 311-316 
Pearse JS, McClary DJ, Sewell MA, Austin WC, Perez-Ruzafa A, Byrne M (1988) Simultaneous spawning of six species of echinoderms in Barkley Sound, British Colombia. Int J Invertebr Reprod 14:279-288

Richmond RH, Hunter CL (1990) Reproduction and recruitment of corals: comparisons among the Caribbean, the tropical Pacific, and the Red Sea. Mar Ecol Prog Ser 60: 185-203

Robertson DR, Petersen CW, Brawn JD (1990) Lunar reproductive cycles of benthic brooding reef fishes: reflections of larval biology or adult biology? Ecol Monogr 60:311-329

Shepherd SA, Martinez P, Toral-Granda MV, Edgar GJ (2004) The Galapagos sea cucumber fishery: management improves as stocks decline. Environ Conserv 31:102-110

Smiley S, McEuen FS, Chaffe C, Krishnan S (1991) Echinodermata: Holothuroidea. In: Giese AC, Pearse JS, Pearse VB (eds) Reproduction of marine invertebrates, Vol VI. Echinoderms and Lophophorates. The Boxwood Press, Pacific Grove, CA, p 663-750

Sonnenholzner J (1997) A brief survey of commercial sea cucumber Isostichopus fuscus (Ludwig, 1875) of the Gala-

Editorial responsibility: Don Levitan (Contributing Editor), Tallahassee, Florida, USA pagos Islands, Ecuador. SPC Beche-de-Mer Inf Bull 9: $2-15$

Szmant AM (1991) Sexual reproduction by the Caribbean reef corals. Coral Reefs 5:43-53

Takemura A, Susilo ES, Rahman MS, Morita M (2004) Perception and possible utilization of moonlight intensity for reproductive activities in a lunar-synchronized spawner, the golden rabbitfish. J Exp Zool 301A:844-851

Tanner JE (1996) Seasonality and lunar periodicity in the reproduction of Pocilloporid corals. Coral Reefs 15:59-66

Toral-Granda VG, Martinez PC (2004) Population density and fishery impacts on the sea cucumber (Isostichopus fuscus) in the Galapagos marine reserve. In: Lovatelli A, Conand C, Purcell S, Uthicke S, Hamel JF, Mercier A (eds) Advances in sea cucumber aquaculture and management. FAO Fish Tech Pap No. 463. FAO, Rome, p 91-100

Watson GJ, Williams ME, Bentley MG (2000) Can synchronous spawning be predicted from environmental parameters? A case study of the lugworm Arenicola marina. Mar Biol 136:1003-1017

Submitted: January 23, 2006; Accepted: June 19, 2006 Proofs received from author(s): December 8, 2006 